Article

\title{
Study of the Shielding Interactions between Double Cracks on Crack Growth Behaviors under Fatigue Loading
}

\author{
Zhichao Han ${ }^{(}$, Caifu Qian and Huifang $\mathrm{Li}^{*}$ \\ Institute of mechanical and electrical engineering, Beijing University of Chemical Technology, Beijing 100029, \\ China; hanzhichaohzc@163.com (Z.H.); qiancf@mail.buct.edu.cn (C.Q.) \\ * Correspondence: lihf@mail.buct.edu.cn; Tel.: +86-10-64433729
}

Received: 31 December 2019; Accepted: 29 January 2020; Published: 31 January 2020

check for updates

\begin{abstract}
In this paper, the interactions between double cracks with a co-bisector-line were investigated theoretically and experimentally. Fatigue crack growth tests of specimens with a single crack or double cracks were carried out to measure the crack growth rates, and finite element calculations were performed to obtain the stress intensity factors at crack tips. It was found that when the double cracks are in co-bisector-line, they present shielding interactions which reduce the stress intensity factors at crack tips as well as the crack growth rates. By modifying the stress intensity factors and the Paris equation considering the shielding interactions, a new simplification method was proposed to simplify the double cracks into a single crack with the same crack growth rates.
\end{abstract}

Keywords: double cracks; crack interaction; stress intensity factor; crack growth rate

\section{Introduction}

In engineering equipment or components, such as welded joints, ships, aircrafts, pressure vessels, etc., multiple cracks may initiate and grow under the fatigue loading [1-4]. In the initiation and propagation process, cracks may influence and be influenced by the neighboring cracks [5] or, in other words, interactions between multiple cracks exist under the fatigue loading. Traditional fatigue crack propagation models mainly focus on the fatigue crack behavior of a single crack and adopt the driving force to characterize the fatigue crack growth rate [6]. However, for the multiple cracks, the driving force, for example, the stress intensity factor (SIF), should be affected by the interactions between multiple cracks [7]. Neglect of crack interactions will lead to an inaccurate estimate of fatigue levels of engineering components [8-10]. Hence, it is of great importance to investigate the interactions between multiple cracks.

Multiple crack initiation usually occurs in the location with high stress, voids, and impurities [11-13], such as weld joints [14]. Due to the corrosive effect of the environment on the materials, cracks appears in the corrosion pits [15]. Additionally, metallic materials usually contain some coarse microstructures, such as martensite, and multiple cracks can easily generate at these microstructures [16-18]. During crack initiation and propagation, interactions of multiple cracks exist. Gope et al. [19] researched the interactions between two collinear cracks and two offset edge cracks. They found that with increasing crack offset distance $\mathrm{H}$, crack intensification reduced and remained about $10 \%$ higher than the two collinear edge crack configuration. In addition, the stress intensification factor was presented as third degree polynomial function of crack offset distance $H$. Elfakhakhre et al. [20] analyzed the interactions of single and multiple curved cracks in an elastic half plane. Results showed that the closer the cracks to the boundary and the closer the cracks to each other, the higher the SIF. Moussa et al. [21-23] studied the interactions between double non-coplanar, semi-elliptical surface cracks. They found that when the 
interacting cracks were not overlapped, the interaction factors increased as the offset distance decreased. An empirical formula was obtained, which related the position, depth, shape of the cracks, and plate thickness to the SIFs of the double cracks. Isida et al. [24] proposed reliable formulas to describe the relationship between the crack numbers and the SIFs of multiple collinear or parallel cracks under various load conditions. Jiang et al. $[25,26]$ researched double unequal parallel cracks in a finite width plate subjected to a remote tensile load. They found that, because of the crack interactions, the SIFs at the tips of double cracks simultaneously decreased, and when the difference between the lengths of the double cracks was high, the short crack was dormant and its influence could be neglected.

In addition to the SIFs, crack interactions could influence the crack growth behaviors of multiple cracks. Kishida et al. [27] investigated the priority of propagation among three parallel cracks, and they found that the longest crack did not always have the maximum value of the SIF due to the crack interactions. Sun et al. [28] studied the multiple crack propagation behaviors of the tunnel boring machine cutter head. They found that compared with the single crack, the multi-crack propagation paths exhibited a mutual attraction phenomenon, because the stress field around the crack tip was polymerized and tilted, which changed the direction of the principal stress around the crack tip and the crack propagation. Jin et al. [29] found that the crack growth rates of double collinear cracks deviated from those of the single crack. Thus, they introduced a parameter $\Delta K_{\mathrm{n}}$ as the new driving force based on the net section stress range $\Delta \sigma_{\mathrm{n}}$. With the new driving force, all da/dN vs. $\Delta K_{\mathrm{n}}$ curves for the double collinear cracks and single crack were almost completely overlapped. Kamaya et al. [30] studied the interactions between double parallel surface cracks by the fatigue tests and finite element method. They found that the crack growth rates of the double surface cracks were different from those of the single crack. Therefore, basing on the growth area, $A$, they proposed new parameters $\sigma \mathrm{A}^{0.5}$ as the driving force, and $\mathrm{d} A / \mathrm{d} N$ as the new crack growth rate. With the new parameters, all $\mathrm{d} A / \mathrm{d} N$ vs. $\sigma \mathrm{A}^{0.5}$ curves showed little difference among all the parallel surface cracks and single surface crack.

In this study, interactions between double cracks with co-bisector-line were investigated experimentally and numerically. Fatigue experiments were carried out to compare the fatigue crack growth behaviors of a single crack and double cracks. Stress intensity factors at crack tips were calculated with the finite element method. Crack interactions between the double cracks were investigated, and a simplification method was proposed for the crack growth rates by modifying the stress intensity factors and the Paris equation.

\section{Experiment Methodology}

\subsection{Specimen Preparation}

The hot-rolled plates of $\mathrm{S} 30408$ stainless steel were machined into the required dimensions $(260 \mathrm{~mm}$ $\times 48 \mathrm{~mm} \times 6 \mathrm{~mm}$ ). Table 1 lists the position and size of the cracks in different specimens. In order to investigate the crack interactions, seven groups of specimens were specially designed. Figure 1a depicts the size of the specimen with a single crack under a tensile loading (SC). Figure $1 \mathrm{~b}$ illustrates the size of the specimen with double cracks under the same tensile loading. The crack tips of the double cracks are represented with symbols A, B, C, and D, as shown in Figure 1. In Table 1, SC represents the single crack, PC0.5h5 represents the double parallel cracks with $a_{2} / a_{1}=0.5$ and $h=5 \mathrm{~mm}, \mathrm{OC} 0.9 \mathrm{~h} 6.1$ represents double oblique cracks with $a_{2} / a_{1}=0.9$ and $h=6.1 \mathrm{~mm}$, and so on. It is noted that for the double cracks, crack 1 with the length of $2 a_{1}$ is set to be perpendicular to the tensile loading, while crack 2 with the projected length of $2 a_{2}$ is either perpendicular or oblique to the tensile loading, which means that the double cracks are either parallel or oblique to each other. In addition, in this study, the bisector lines of two cracks are the same and coincide with the centerline of the plate. 
Table 1. Position and size of the cracks in seven groups of specimens.

\begin{tabular}{cccccccc}
\hline Specimens & SC & PC0.5h5 & PC0.7h4 & PC0.9h2.5 & PC1.0h2.5 & OC0.9h6.1 & OC1.0h6.5 \\
\hline$a_{1}(\mathrm{~mm})$ & 3 & 3 & 3 & 3 & 3 & 3 & 3 \\
$a_{2}(\mathrm{~mm})$ & - & 1.5 & 2.1 & 2.7 & 3 & 2.7 & 3 \\
$h(\mathrm{~mm})$ & - & 5 & 4 & 2.5 & 2.5 & 6.1 & 6.5 \\
$\alpha\left({ }^{\circ}\right)$ & - & 90 & 90 & 90 & 90 & 36.7 & 36.7 \\
\hline
\end{tabular}

(a)

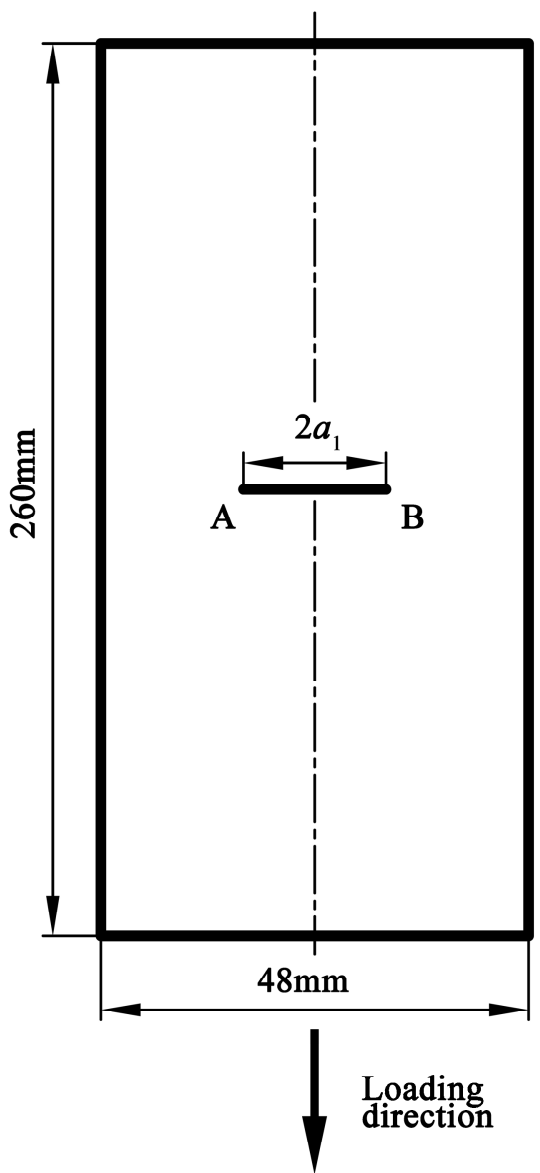

(b)
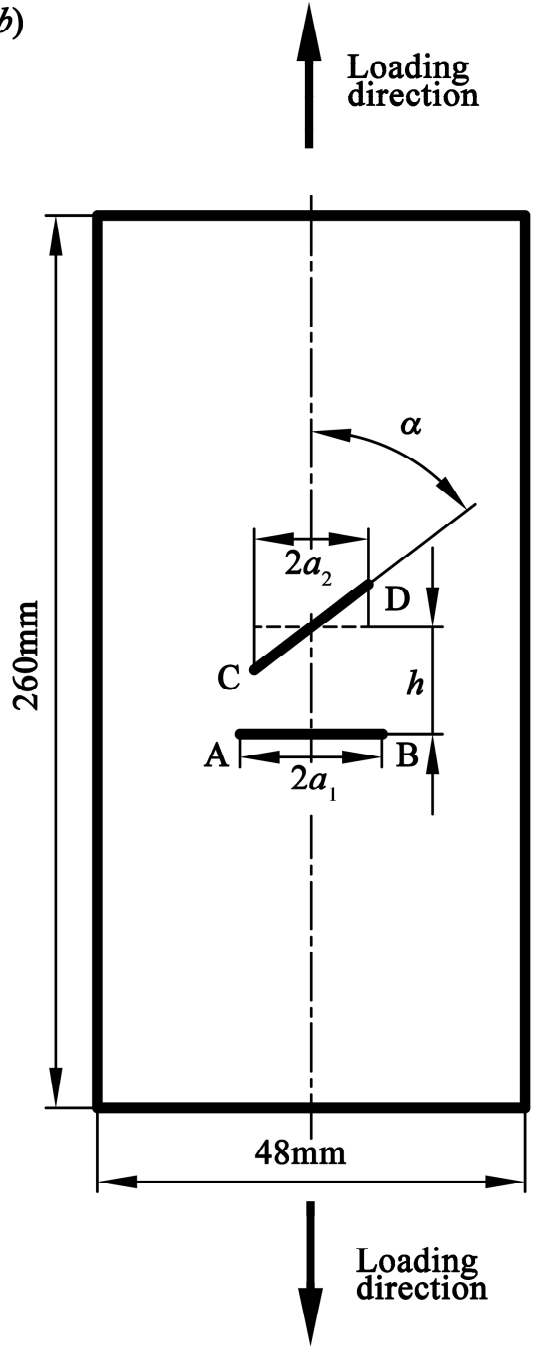

Figure 1. Geometry of the test specimens: (a) Single crack specimen; (b) double crack specimen.

\subsection{Settings of the Fatigue Test}

Fatigue crack growth tests were carried out on an INSTRON 8800 fatigue testing machine (Boston, MA, USA). Constant amplitude fatigue load with the stress ratio of 0.1 , maximum load of $40 \mathrm{kN}$, and a frequency of $45 \mathrm{~Hz}$ was applied [31]. The digital microscope system (Mshot MS60, Guangzhou, China) was used to monitor and record the fatigue crack growth paths and rates.

\section{Results of the Tests}

\subsection{Crack Growth Paths}

Figure 2 shows the crack growth paths in the SC, PC0.5h5, PC0.7h4, PC0.9h2.5, and PC1.0h2.5 specimens. Figure 3 shows the crack growth paths in the OC0.9h6.1 and OC1.0h6.5 specimens. 

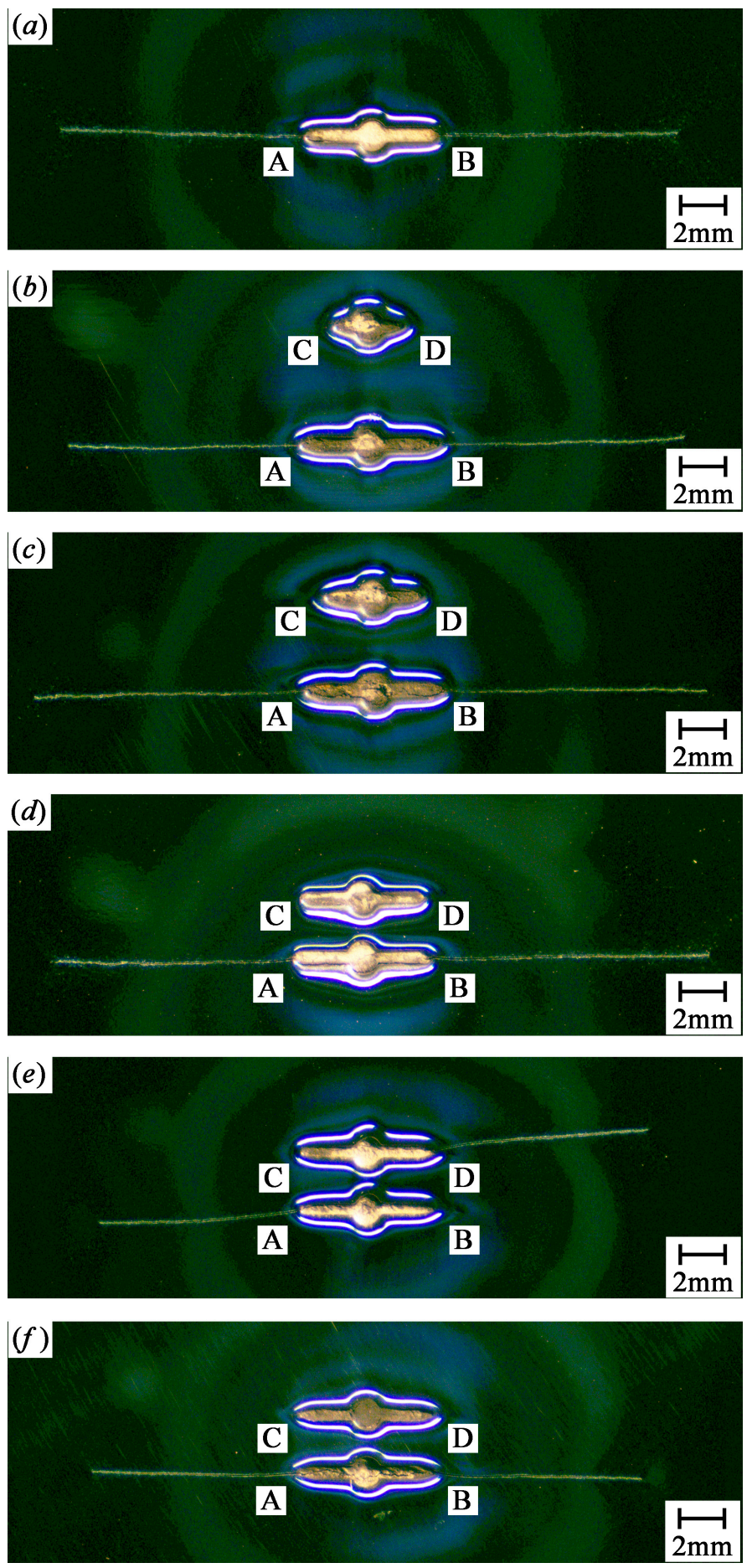

Figure 2. Crack growth paths in different specimens: (a) SC; (b) PC0.5h5; (c) PC0.7h4; (d) PC0.9h2.5; (e), and (f) PC1.0h2.5. 

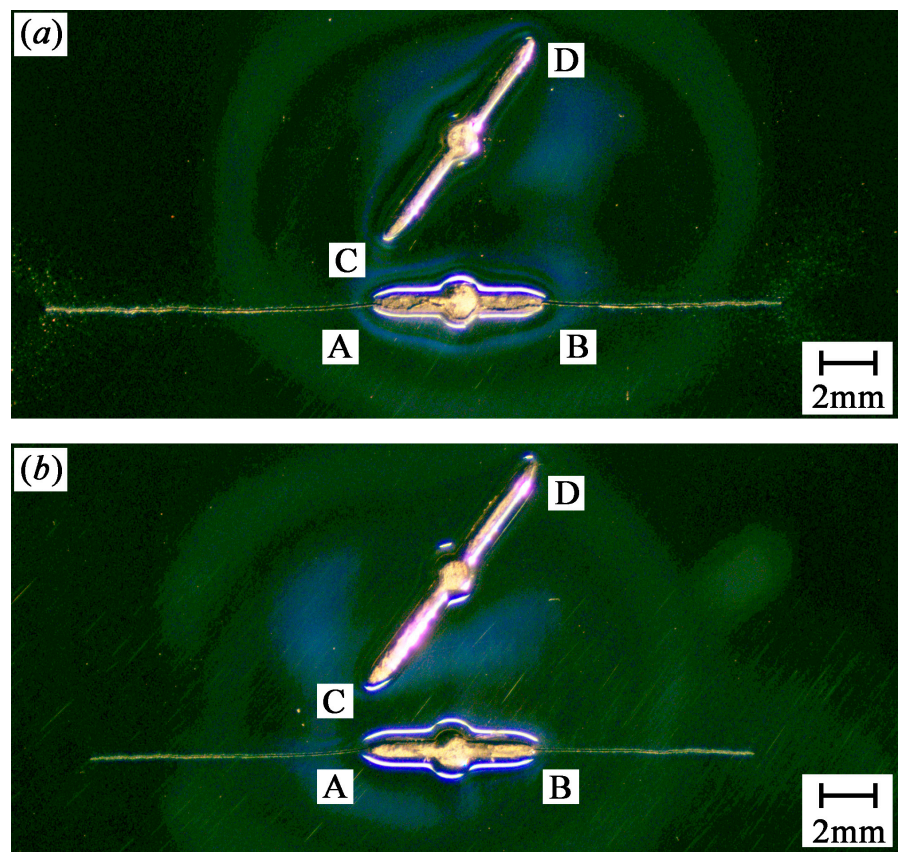

Figure 3. Crack growth paths in different specimens: (a) OC0.9h6.1; (b) OC1.0h6.5.

From Figures 2 and 3, it is found that the crack growth paths are perpendicular to the loading direction. For the PC0.5h5, PC0.7h4, and PC $0.9 \mathrm{~h} 2.5$ specimens, only crack 1 , or the dominant crack, which has the longer projected length in the direction perpendicular to the loading direction grows continuously, as shown in Figure $2 \mathrm{~b}-\mathrm{d}$, while the short crack, or crack 2, is in the dormant state due to the shielding effect of the long crack. For the PC1.0h2.5 specimens where the two cracks are parallel and have the same length as shown in Figure 2e-f, the fatigue crack grows in two possibilities, either from tips of one crack or from tips of two cracks, while all other tips are dormant due to the shielding effects between the two cracks. For the OC0.9h6.1 and OC1.0h6.5 specimens, however, as shown in Figure 3, only the crack perpendicular to the loading direction, or the dominant crack, grows continuously, while the oblique crack is in the dormant state due to the shielding effect of the dominant crack.

\subsection{Crack Growth Length}

In order to show the different shielding effects on the two tips of the dominant crack more clearly, crack growth length, $a_{x}$, for the cycle number, $N$, beginning at the same crack length was measured and plotted in Figure 4. The growth length at the two tips of the single crack was also plotted for comparison. Especially, for the double parallel crack specimens, the growth length changing with the cycle number at crack tips A and B (crack tips A and D for Figure 2e) of the dominant crack was plotted with the same symbols for the same specimens, as shown Figure 4a, while for the double oblique crack specimens, it was plotted with different symbols for the same specimens, as shown Figure $4 \mathrm{~b}$. It is seen from Figure 4a that for the given cycle number the crack growth length of the dominant cracks in all the double crack specimens is shorter than that of the single crack, meaning that the two cracks present shielding effects between each other. The larger the ratio of $a_{2} / a_{1}$ and the closer the two cracks, the shorter the growth length of the dominant cracks compared with the single crack, meaning that the more significant shielding effects are. In addition, it is found from Figure $4 \mathrm{~b}$ that for the same cycles, because of the different shielding effects on the two tips of the dominant crack by the oblique crack, the crack growth length at tip A of the dominant crack is larger than that at tip B. 

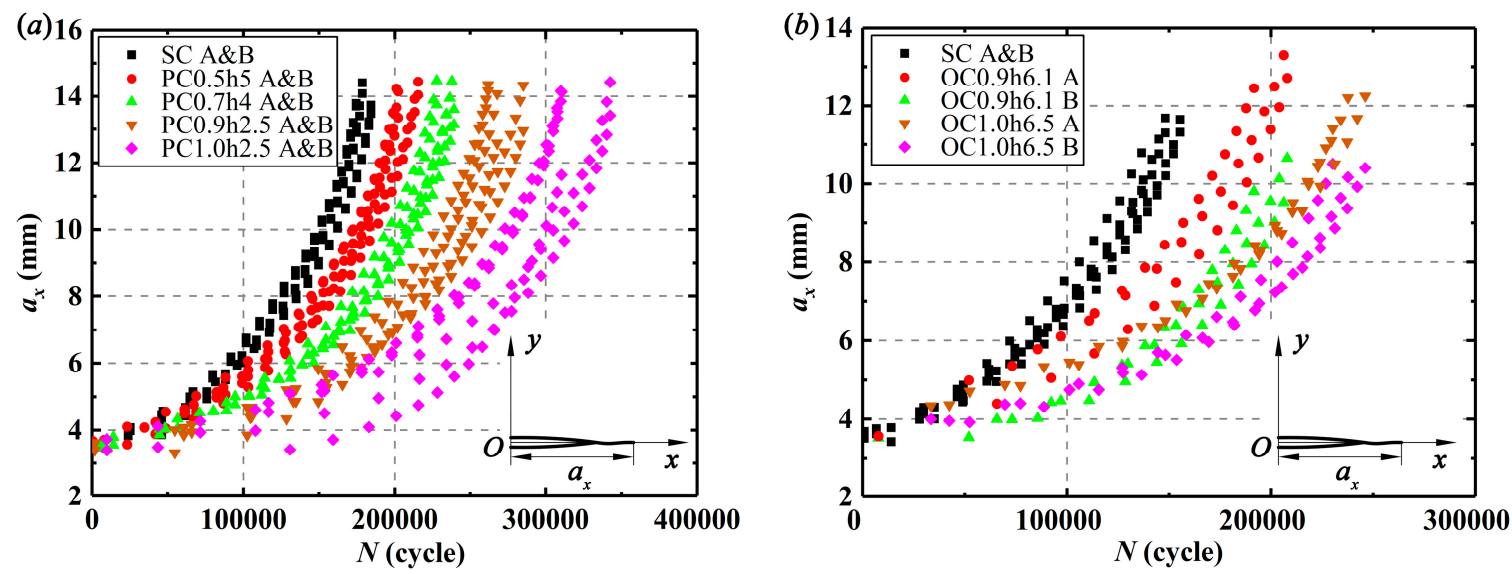

Figure 4. Crack growth length vs. number of cycles: (a) for different crack configurations; (b) for different tip.

\section{Numerical Simulations}

\subsection{Finite Element Modeling}

In this study, stress intensity factors at crack tips are used to represent the driving force for crack propagation. For the infinite plate with double cracks in the configuration studied here, no accurate solutions are available. Thus, the finite element method (FEM) is applied to compute the stress intensity factors at crack tips. Figure 5 shows the geometric model of a plate with double cracks.
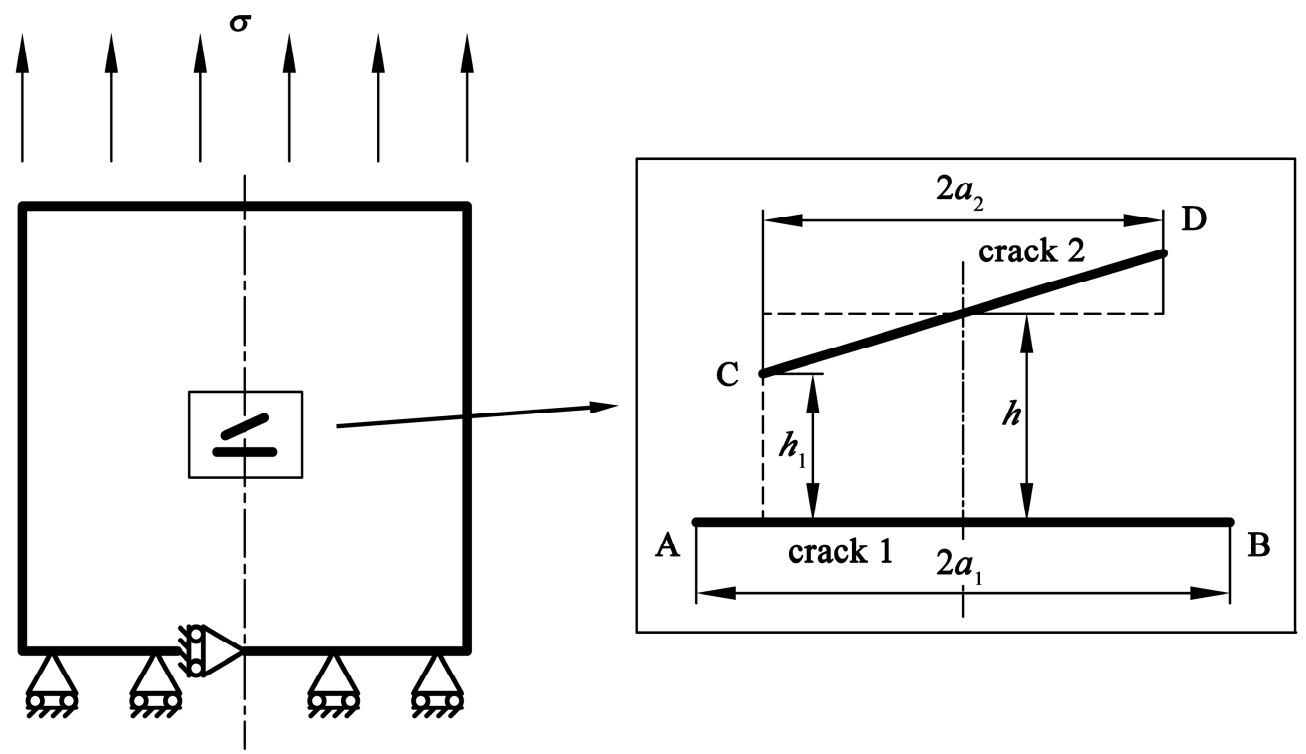

Figure 5. Geometric model of a plate with double cracks.

The eight-node plane element, PLANE 183 element, with the software ANSYS (version 18.0, ANSYS Inc., Canonsburg, PA, USA) is adopted to generate meshes of the finite element model. As shown in Figure 6, in the region around the crack tips, meshes are refined to improve the calculation accuracy of finite element simulation. A special command in ANSYS, the KSCON (key point stress concentration) command, is executed to generate the singular elements at the crack tips. The mid-nodes of the singular elements at the crack tip are skewed to the $1 / 4$ point. The size of singular elements at crack tips is $1 / 10$ of the crack length. Twenty singular elements are created at each crack tips, and the SIFs of the crack tips are calculated by the displacement extrapolation method [32]. In order to ensure 
the accuracy of the numerical calculation, mesh independence is verified. Values of $K_{\mathrm{I}}$ at crack tip A for $R a=0.9, H_{1}=1$, and $H=0.833$ are calculated by the FEM for the different size of single element, $a_{1} / 5, a_{1} / 10$, and $a_{1} / 20$. Additionally, the value of $K_{\mathrm{I}}$ at crack tip A by the method of Kuang et al. [33] is also listed in Table 2 . The errors in Table 2 is calculated based the size of singular element, $a_{1} / 10$. It can be found from the table that the all the errors are relatively small, and the singular element size, $a_{1} / 10$, is applicable to calculate the SIFs of the double crack.

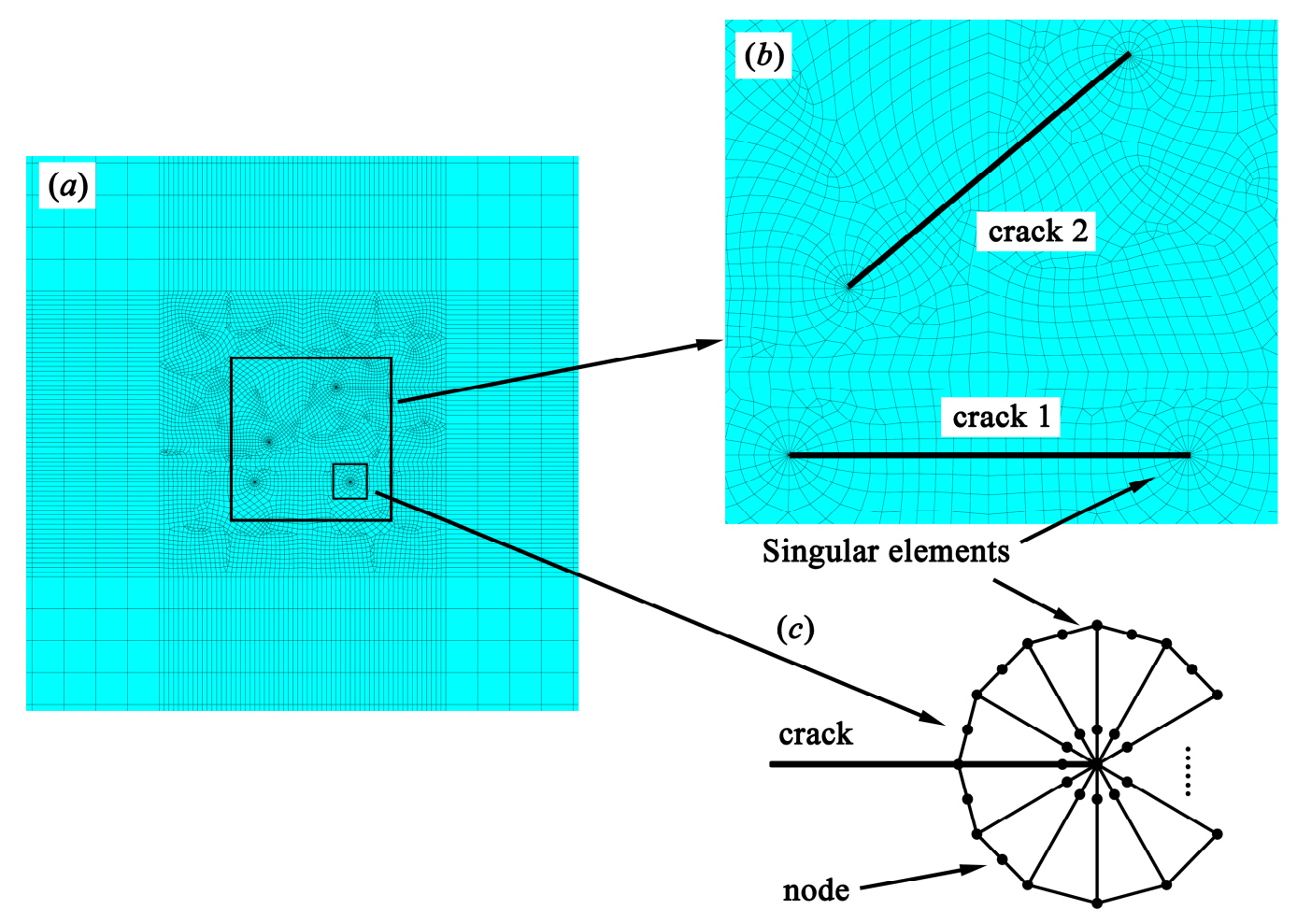

Figure 6. Mesh model of the plate with double cracks: (a) Global mesh; (b) mesh at the vicinity of the crack tips; (c) singular elements at crack tips.

Table 2. Accuracy verification of the size of the singular element.

\begin{tabular}{|c|c|c|c|c|}
\hline Size of Singular Element & $a_{1} / 5$ & $a_{1} / 10$ & $a_{1} / 20$ & Kuang et al. [33] \\
\hline$K_{\mathrm{I}}\left(\mathrm{MPa} \cdot \mathrm{m}^{1 / 2}\right)$ & 10.056 & 10.062 & 10.068 & 10.075 \\
\hline Error $(\%)$ & 0.06 & - & 0.05 & 0.12 \\
\hline
\end{tabular}

\subsection{Simulation Results of the SIFs}

As mentioned above, for the double cracks, crack 1 is a dominant crack, which has a longer project length than crack 2, i.e., $a_{2} \leq a_{1}$. As depicted in Figure 5, the distance of crack tips $\mathrm{C}$ to crack 1 is denoted by $h_{1}$, and the distance of the midpoint of crack 2 to crack 1 is denoted by $h$. Clearly, if $h_{1}=h$, the two cracks are parallel, otherwise they are oblique to either other. As the cracks propagate in Mode I as shown in Figures 2 and 3, Mode I stress intensity factors, $K_{\mathrm{I}}$, at both crack tip A and tip B of the crack 1 are calculated. For comparison, the SIF at a single crack with the length of $2 a_{1}$ in an infinite plate subjected to the same remote stress is also calculated by Equation (1):

$$
K_{\mathrm{I}}^{0}=\sigma \sqrt{\pi a_{1}}
$$


To evaluate the shielding effects of crack 2 on the SIFs of crack 1, a so-called reduction coefficient, $K_{R}$, is defined by Equation (2):

$$
K_{R}=\frac{K_{\mathrm{I}}}{K_{\mathrm{I}}^{0}}
$$

The reduction coefficient, $K_{R}$, should be the function of the geometrical parameters, $h, h_{1}, a_{1}$ and $a_{2}$. In order to find expressions for $K_{R}$, three dimensionless numbers, i.e., $H, H_{1}$, and $R a$, are introduced by Equations (3)-(5):

$$
\begin{aligned}
H & =\frac{h}{a_{1}} \\
H_{1} & =\frac{h_{1}}{h} \\
R a & =\frac{a_{2}}{a_{1}}
\end{aligned}
$$

Figure 7 shows the changes of $K_{R}$ at tip A with the increasing $H$ for different $R a$ when $H_{1}=1$ or, in other words, the double cracks are parallel to each other. It is found that the values of $K_{R}$ are less than 1, meaning that the crack 2 affords a shielding effect on the SIFs of the crack 1 . When the ratio of two crack length, $R a$, is less than 1 , with increasing $H$ or $h$ for a given crack length $a_{1}, K_{R}$ decreases first and then increases or, in other words, the shielding effect increases first and then decreases. On the other hand, when the two cracks are far enough, the shielding effect is vanishing. In addition, it is found that when $R a<0.5$, the effect of the crack 2 on the SIFs of the crack 1 can be neglected. When the value of $R a$ is equal to $1, K_{R}$ increases with the increasing $H$ monotonously.

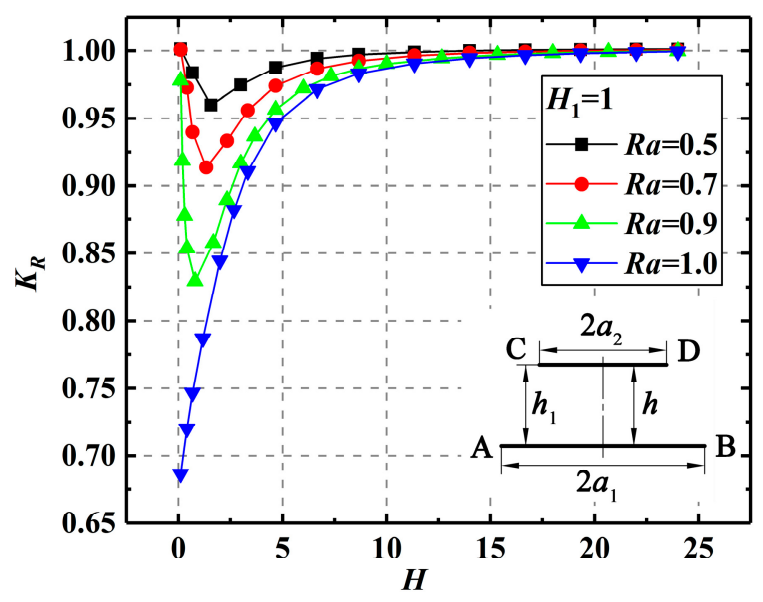

Figure 7. Changes of $K_{R}$ with $H$ for different $R a$.

It turns out that corresponding the minimum values of $K_{R}$ in Figure 7 for the strongest shielding effects, the values of $H$ can be expressed by Equation (6):

$$
H_{c}=1.546\left(1-R a^{6.486}\right)
$$

Figure 8 shows the changes of $K_{R}$ at tip A with the increasing $H_{1}$ for different $H$ when $R a=1.0$. It is seen that $K_{R}$ decreases with increasing $H_{1}$, which means that as the tip $C$ of the crack 2 gets farther from the crack 1 compared with the tip D, the shielding effect of the crack 2 on tip A of the crack 1 is becoming smaller and smaller. 


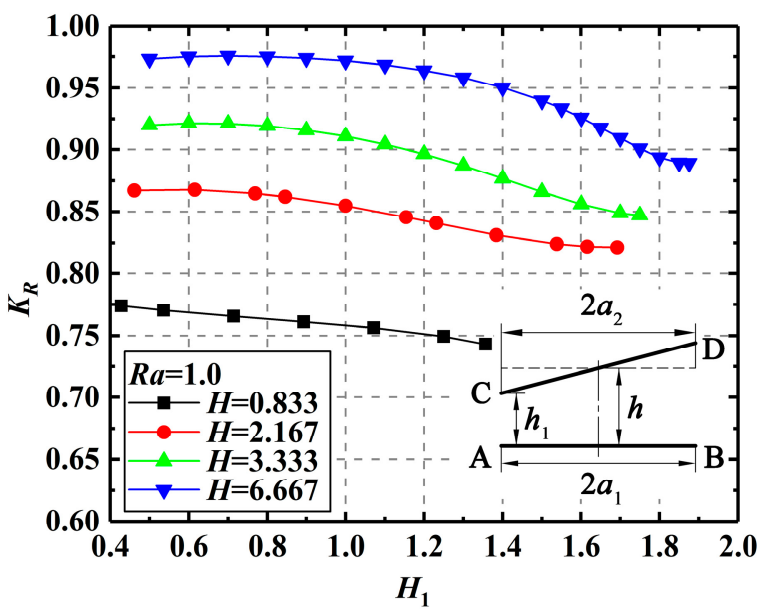

Figure 8. Changes of $K_{R}$ at tip A with $H_{1}$ for different $H$.

With $H, H_{1}$, and $R a$, based on sufficient numerical results, $K_{R}$ of crack tip A can be obtained by the least square method and expressed as follows:

$$
\left\{\begin{array}{c}
\text { for } H \leq H_{c} \\
K_{R}=\left(1.012-0.472 R a^{3.255} \frac{H}{H+0.579}\right)\left(\frac{0.878+H_{1}}{0.785+1.114 H_{1}}+0.010 H_{1}\right) \\
\quad \text { for } H>H_{\mathcal{c}} \\
K_{R}=\left(0.998-0.319 R a^{2.251} e^{-0.375 H}\right)\left(\frac{1}{3.076+0.158 H_{1}^{2.496}}+0.686\right)
\end{array}\right.
$$

Especially, when the value of $H_{1}$ is equal to 1 , the factors which include the parameter, $H_{1}$, in Equations (7) and (8) are equal to 1, implying that the first factors in the two equations are meaningful for the double parallel cracks. Equations (7) and (8) are valid for $0.5 \leq R a \leq 1$ and $\min \left(h, h_{1}\right) \geq 0.2 a_{1}$.

With $K_{R}$ obtained from Equations (7) and (8), and by applying Equations (1) and (2), stress intensity factors at the dominant crack tips with consideration of the shielding effects of the other crack can be easily calculated. Table 3 lists the relative errors of the stress intensity factors obtained by Equations (7) and (8) compared with FEM for $R a=0.5,0.7,0.9$, and 1.0. It is seen that in general, the relative errors for $R a=1.0$ are less than $9.5 \%$, and the relative errors for $R a \leq 0.9$ are less than $7.0 \%$, which is acceptable in engineering.

Table 3. Numerical verification of Equations (7) and (8) for the SIFs at crack tip A.

\begin{tabular}{|c|c|c|c|c|c|}
\hline$R a$ & $H$ & $H_{1}$ & $\begin{array}{l}\text { Values of } K_{\mathrm{I}} \text { by FEM } \\
\qquad\left(\mathrm{MPa} \cdot \mathrm{m}^{1 / 2}\right)\end{array}$ & $\begin{array}{l}\text { Values of } K_{\mathrm{I}} \text { by Equations (7) and (8) } \\
\qquad\left(\mathrm{MPa} \cdot \mathrm{m}^{1 / 2}\right)\end{array}$ & $\begin{array}{c}\text { Error } \\
(\%)\end{array}$ \\
\hline 0.5 & 1.767 & 0.113 & 12.572 & 12.062 & 4.06 \\
\hline 0.7 & 1.433 & 0.140 & 12.423 & 11.592 & 6.66 \\
\hline 0.9 & 0.933 & 0.214 & 11.118 & 10.400 & 6.46 \\
\hline 1.0 & 0.600 & 0.333 & 8.495 & 9.271 & 9.13 \\
\hline
\end{tabular}

It is noted that the Equations (7) and (8) can also be applied to calculate the value of $K_{R}$ at crack tip B where $h_{1}$ is the distance from tip D to the crack 1.

Specially, for specimens PC0.5h5, PC0.7h4, PC0.9h2.5, and PC1.0h2.5, $K_{R}$ at crack tip A or B is $0.960,0.914,0.829$, and 0.761 , respectively. For the specimen OC0.9h6.1, $K_{R}$ at crack tip A and B is 0.911 and 0.847 , respectively. For the specimen OC1.0h6.5, $K_{R}$ at crack tip A and B is 0.870 and 0.824 , respectively. As a smaller $K_{R}$ corresponds a larger shielding effect or a smaller stress intensity factor, these results are all consistent with the experimental results for the crack growth as shown in Figure 4 . 


\subsection{Mechanical Explanation of the Shielding Effects}

In order to find out the mechanism of the shielding effects shown in Figure 7, distributions of the tensile stress along the loading direction around the crack tips are investigated. Figures 9 and 10 show the tensile stress distributions with $R a=0.7$ and $R a=1.0$. It is found from Figure 9 a that for the double unequal cracks, when the distance of the two cracks is very close, the short crack has little effect on the long crack because the short crack itself is completely shielded by the dominant crack. As the distance of the cracks increases, the shielding effect on the long crack increases because the "tensile stress" has to bypass the short crack and then act on the long crack, leading to the low stress region of the long crack increasing. The shielding effect of the short crack to the long crack will reach the maximum, as shown in Figure 9b. After that, as the distance between cracks continues to increase, the shielding effect on the long crack decreases as shown in Figure 9c, and if the distance between cracks are far enough, the shielding effect vanishes. However, as shown in Figure 10, for the double parallel cracks with the same length, when they are very close, they strongly shield each other, and with increasing their distance, the shielding effect decreases accordingly.
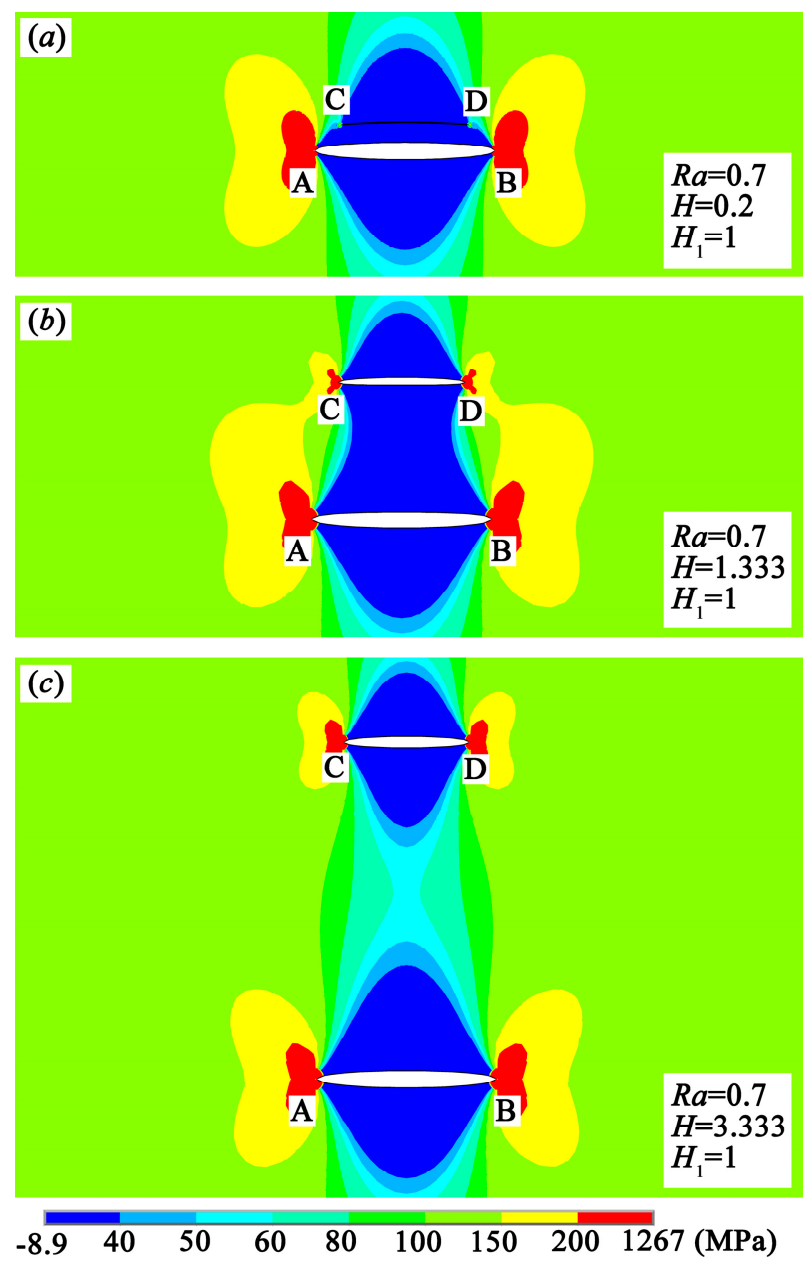

Figure 9. Tensile stress distributions for the double parallel crack with $R a=0.7$ and $H_{1}=1$ : (a) $H=0.2$; (b) $H=1.333$; (c) $H=3.333$. 

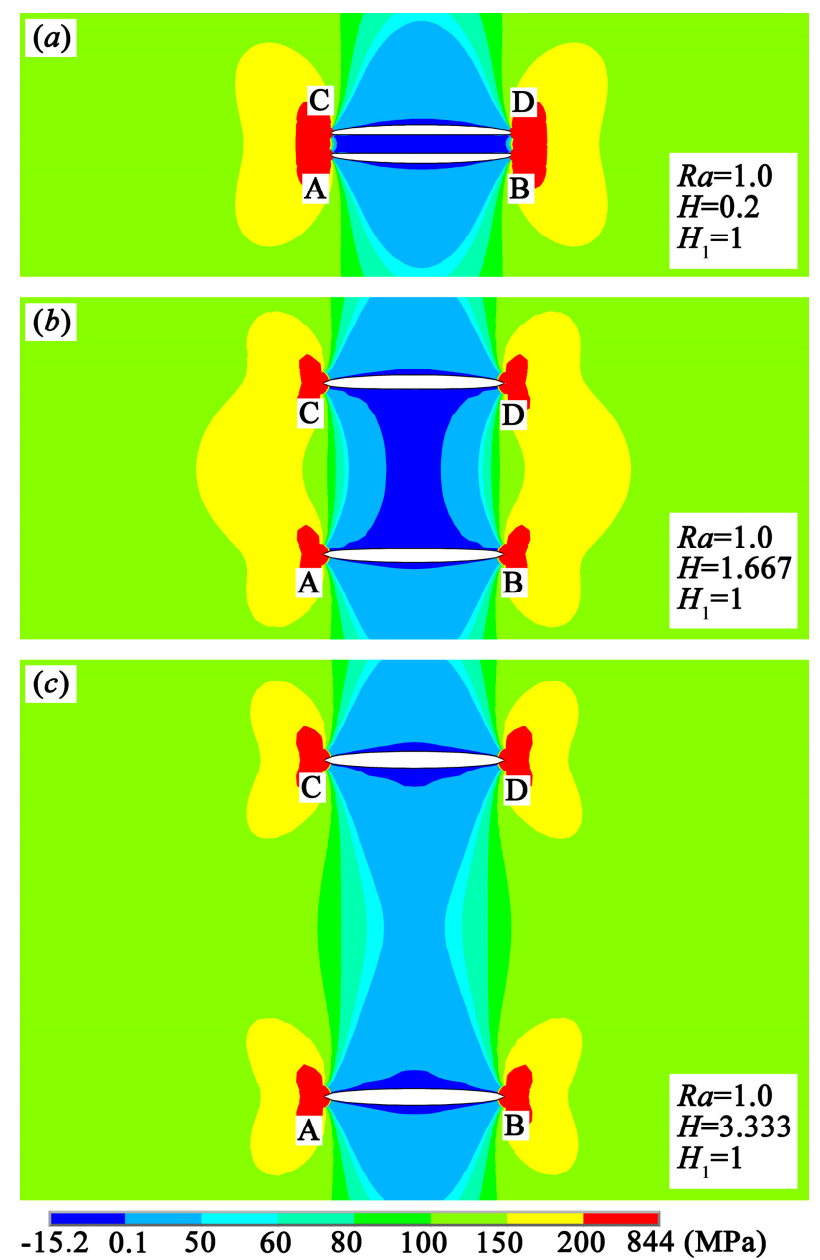

Figure 10. Tensile stress distributions for the double parallel crack with $R a=1.0$ and $H_{1}=1$ : (a) $H=0.2$; (b) $H=1.667$; (c) $H=3.333$.

Similarly, for the double oblique cracks as shown in Figure 11, the two tips of the dominant crack are differently shielded by the oblique crack. Clearly, the tensile stress ahead of the dominant crack tip closer to the oblique crack is stronger than that ahead of the other crack tip, which well explains the crack growth results as shown in Figure $4 b$.

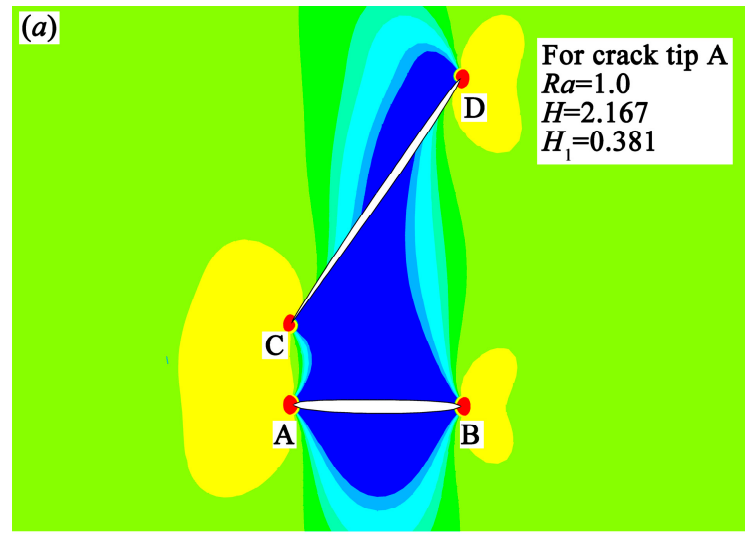

$\begin{array}{rrrrrrrrr}-143 & 40 & 50 & 70 & 80 & 100 & 150 & 300 & 776\end{array}(\mathrm{MPa})$

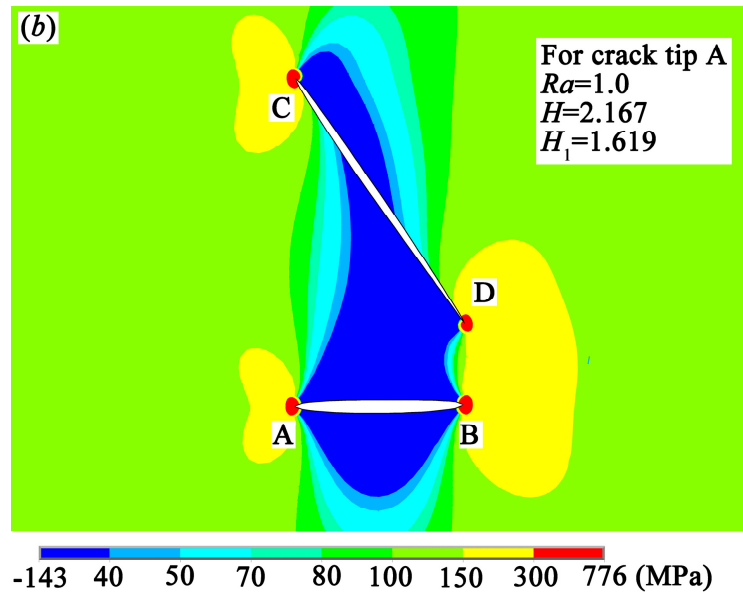

Figure 11. Tensile stress distributions for the double oblique crack: (a) $H_{1}=0.381$; (b) $H_{1}=1.619$. 
To illustrate the shielding effects from the mechanical point of view more clearly, a circle with the center at tip $\mathrm{A}$ or $\mathrm{B}$ and the radius, $r$, of $a_{1} / 20$ is chosen to compare the hoop stress distributions in the vicinity of the crack tips for different crack configurations. The hoop stress in the vicinity of crack tip B for SC, $R a 0.7\left(H=2.097, H_{1}=1.431\right), R a 0.9\left(H=2.102, H_{1}=1.427\right)$ and $R a 1.0\left(H=1.149, H_{1}=\right.$ 1.044) is drawn in Figure 12a. The values of $K_{R}$ at crack B for $R a 0.7, R a 0.9$, and $R a 1.0$ are 0.916, 0.824, and 0.719 , respectively, implying that the shielding effect at tip B of $R a 1.0$ is the largest and that of $\mathrm{Ra} 0.7$ is the smallest. The maximum hoop stresses are at the position around $0^{\circ}$, implying that the crack growth paths are along the crack faces, and the shielding effects hardly affect the crack growth direction. The values of the hoop stress in the vicinity of tip B of the single crack are larger than those of the double cracks, and the hoop stress decreases in the order of $R a 0.7, R a 0.9$, and $R a 1.0$. These results indicate that the shielding effects of the cracks reduce the hoop stresses in the vicinity of the crack tips, and the hoop stresses decrease with the increasing of the shielding effect between the cracks. Figure $12 \mathrm{~b}$ shows the hoop stress in the vicinity of the crack tip A or B for $R a 0.7$ and $R a 0.9$. It is found that due to the different shielding effects by the oblique crack, the hoop stress at tip A is larger than that at tip B, which explains the experimental observation of the crack growth results as shown in Figure 4 .
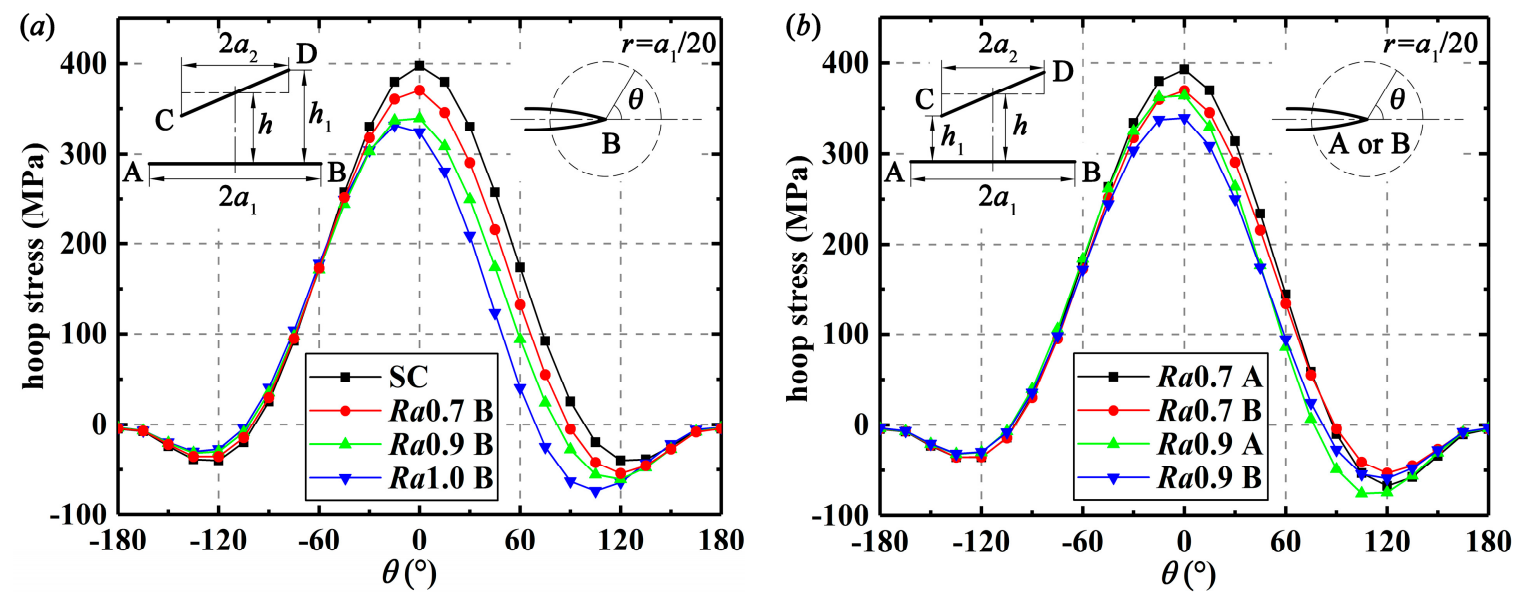

Figure 12. Hoop stress distributions around the crack tips: (a) For different specimens; (b) for different tips.

\section{Crack Growth Rates}

For single crack propagation, the relationship between the crack growth rate, $\mathrm{d} a / \mathrm{d} N$, and the driving force, $\Delta K_{\mathrm{I}}$, is usually described by the Paris equation. With the experimental data for crack growth rates and finite element calculation results for stress intensity factors, fitted $\mathrm{d} a / \mathrm{d} N-\Delta K_{\mathrm{I}}$ curves are respectively plotted in figures in Appendix A for the seven groups of specimens and are all shown in Figure 13. Clearly, at a given $\Delta K_{\mathrm{I}}$, the single crack presents a higher crack growth rate than the double cracks. The more the shielding effects, the more the differences of the crack growth rates between the single crack and double cracks. With the propagation of the dominant cracks, the deviation of the crack growth rates of the dominant cracks from those of the single cracks gets smaller, since the shielding effects from the other crack are decreasing as the crack tips of the crack 1 are getting far and far away from the crack 2. Similar results were also reported by other researchers. For example, Jin et al. [29] and Kamaya et al. [30] found that the crack growth rates of double cracks were different from those of the single crack for the same $\Delta K_{\mathrm{I}}$. 

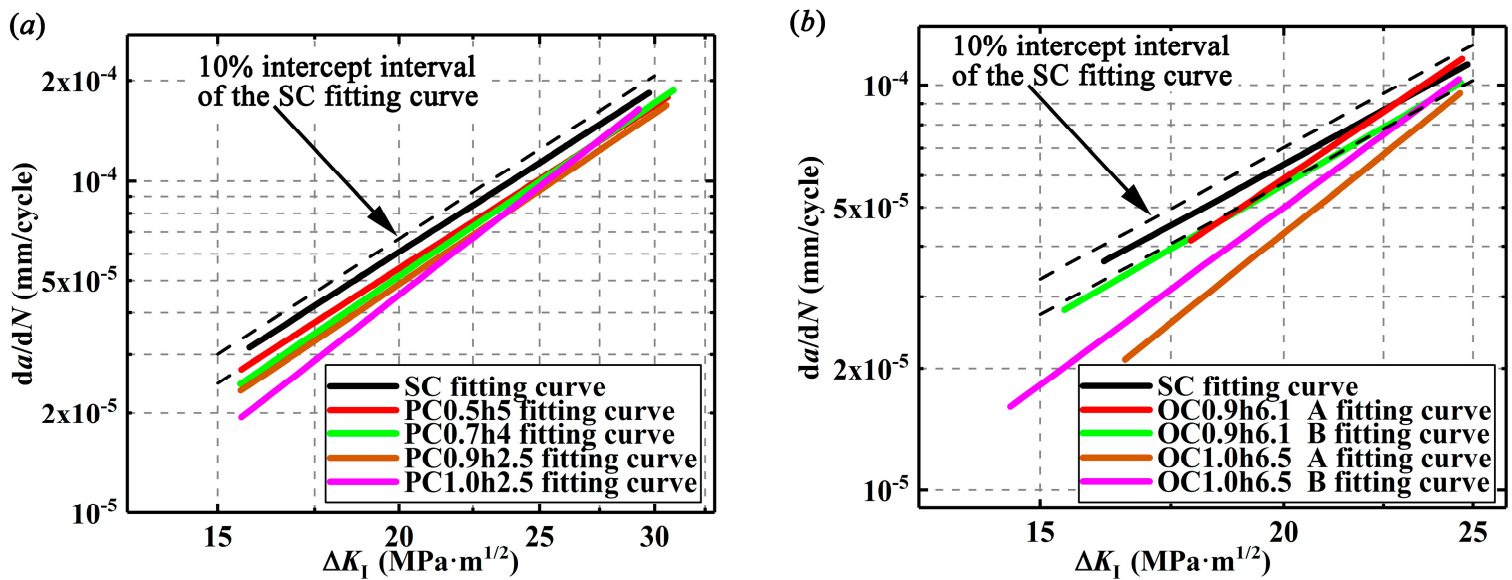

Figure 13. Fatigue crack growth rates versus $\Delta K_{\mathrm{I}}$ : (a) In single crack and double parallel crack specimens; (b) in single crack and double oblique crack specimens.

Considering that $\Delta K_{\mathrm{I}}$ in these figures have considered the shielding effects, deviation of $\mathrm{d} a / \mathrm{d} N-\Delta K_{\mathrm{I}}$ curves for the double cracks means that in terms of the crack growth rates, it is not enough to only modify the stress intensity factors, if the double crack growth rates are described by the Paris equation with the same material parameters $c$ and $m$ as for the single crack.

\section{Simplification of Double Cracks and Discussion}

In engineering, it is a common practice to simplify multi-cracks into a single crack with the same crack growth rates. According to the ASME Boiler and Pressure Vessel Code Section XI [34], if the distance of the double-overlapping cracks is no more than $13 \mathrm{~mm}$, the double cracks with the lengths of $s_{1}$ and $s_{2}$ are considered as a single crack with the length of $s$, as shown in Figure 14. Then the Paris equation of the single crack is applied to evaluate the crack growth rate for the double crack problem. However, it turns out that the ASME method is too conservative.

(a)

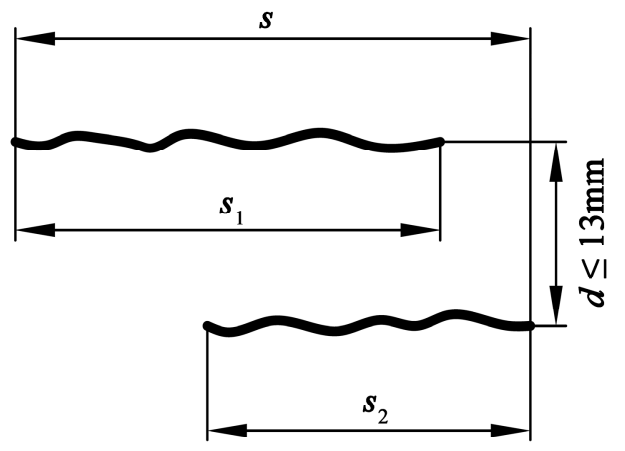

(b)

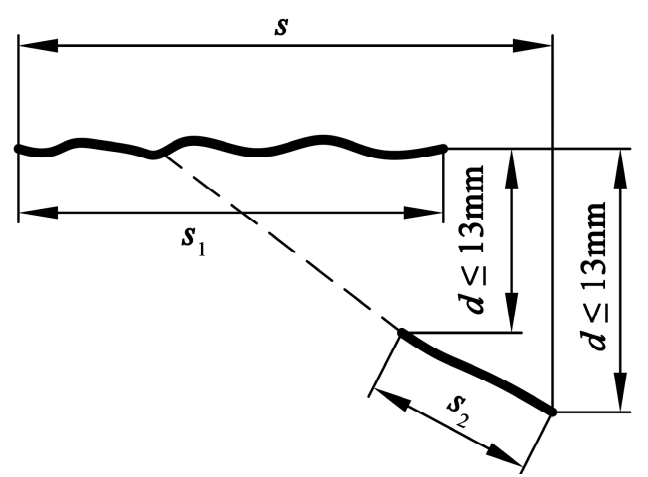

Figure 14. Method for double-overlapping cracks adopted by ASME: (a) Double parallel cracks; (b) double oblique cracks.

In Figure 13, $\mathrm{d} a / \mathrm{d} N-\Delta K_{\mathrm{I}}$ curves of the double cracks show significant differences from that of the single crack, which means that the Paris equation based on a single crack propagation is not suitable to describe the double crack propagation. In fact, fatigue crack growth is related to the damage to the material around crack tip. Crack shielding may not only reduce the crack growth driving force denoted by the stress intensity factor, but also shield the damage to the material, resulting in decrease of crack growth rates. For this reason, in this study the material parameters $c$ and $m$ in the Paris equation for a single crack propagation are modified to be able to apply for double crack propagation. 
With experimental data for crack growth rates and numerical results for stress intensity factors, the parameters $c$ and $m$ in the Paris equation can be modified. For the double parallel crack propagation, the modified $c^{\prime}$ and $m^{\prime}$ are given by Equations (9) and (10) where $K_{R}$ is calculated by Equation (7) or Equation (8). Equations (9) and (10) are obtained by the least square method according to the fitting curves in Figure 13a. Figure 15 shows the modification results where points are experimental data of the dominant crack propagation, the color curves are fitted from these data and the black curves are plotted from the Paris equations which are modified by Equations (9) and (10). Obviously, the curves based on Equations (9) and (10) are within the 10\% intercept interval of the fitting curves from the double parallel crack propagation, implying that with the modified $c^{\prime}$ and $m^{\prime}$ calculated by Equations (9) and (10), the double parallel cracks can be simplified as a single crack having the same crack growth rates:

$$
\begin{gathered}
m \prime=m / K_{R}{ }^{0.722} \\
c \prime=c / K_{R}^{0.414}
\end{gathered}
$$
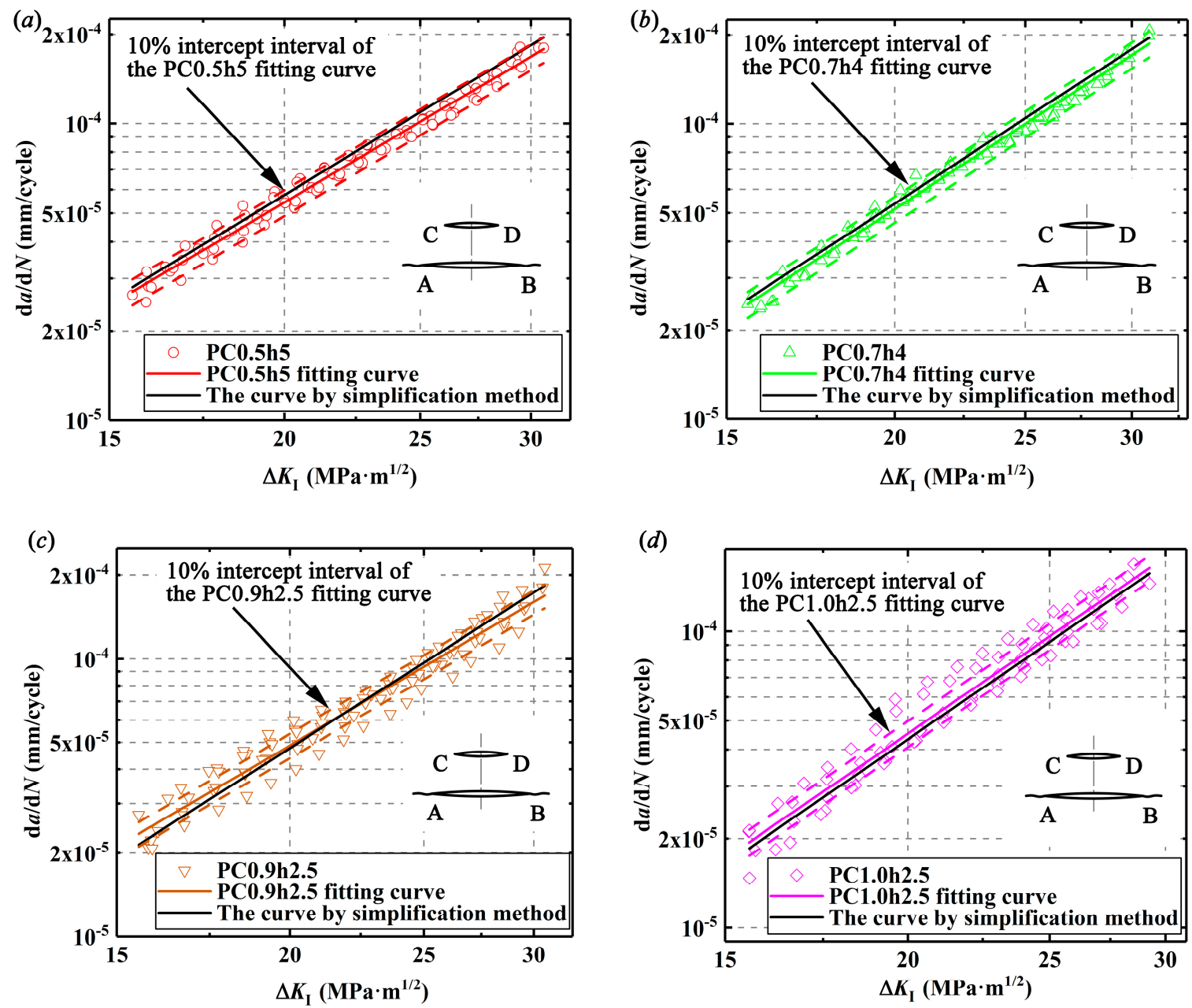

Figure 15. Simplification results for the double parallel cracks: (a) in PC0.5h5 specimens; (b) in PC0.7h4 specimens; (c) in PC0.9h2.5 specimens; (d) in PC1.0h2.5 specimens.

For the double oblique crack propagation, further modifications are needed since the two tips of the dominant crack are differently shielded by the crack 2 and propagate with different rates. In this study, from the conservative point of view, only crack tip with a faster propagation is taken into consideration. Specifically, in Figure 5, tip A is concerned, and the driving force, $\Delta K_{\mathrm{I}}$, is calculated by considering the crack growth length of crack tip A as the half growth length of the dominant crack, 
as shown in Figure 16. By introducing another factors related to the dimensionless number $H_{1}$ in Equations (9) and (10), Equations (11) and (12) are given for describing the crack growth rate at tip A. Similarly, Equations (11) and (12) are obtained by the least square method according to the fitting curves in Figure 16. It is found from Figure 16 that with the modified $c^{\prime}$ and $m^{\prime}$ calculated by Equations (11) and (12), the double oblique cracks can be simplified as a single crack with the same crack growth rates. Clearly, it is seen that the errors between the double crack growth rates (color curves) and the modified single crack growth rates (black curves) are less than $10 \%$, which is acceptable in engineering:

$$
\begin{gathered}
m \prime=m /\left(K_{R}^{0.722} H_{1}^{0.190}\right) \\
c \prime=c /\left(K_{R}^{0.414} H_{1}^{0.106}\right)
\end{gathered}
$$

(a)

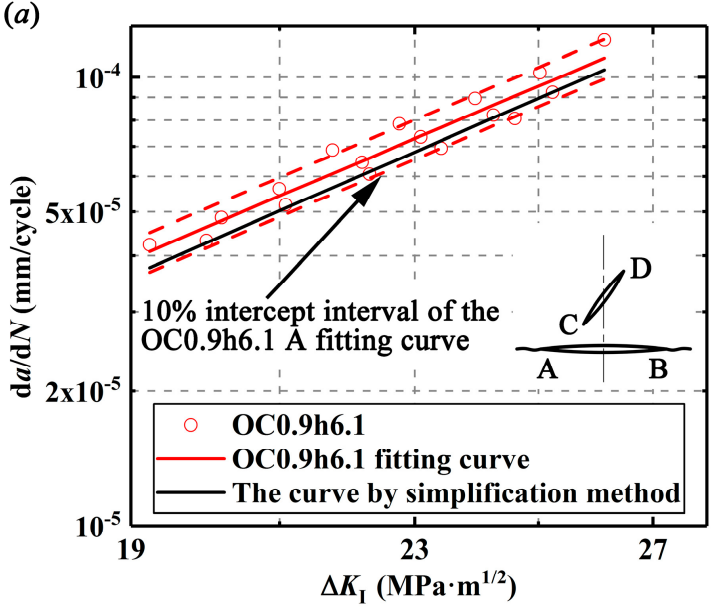

(b)

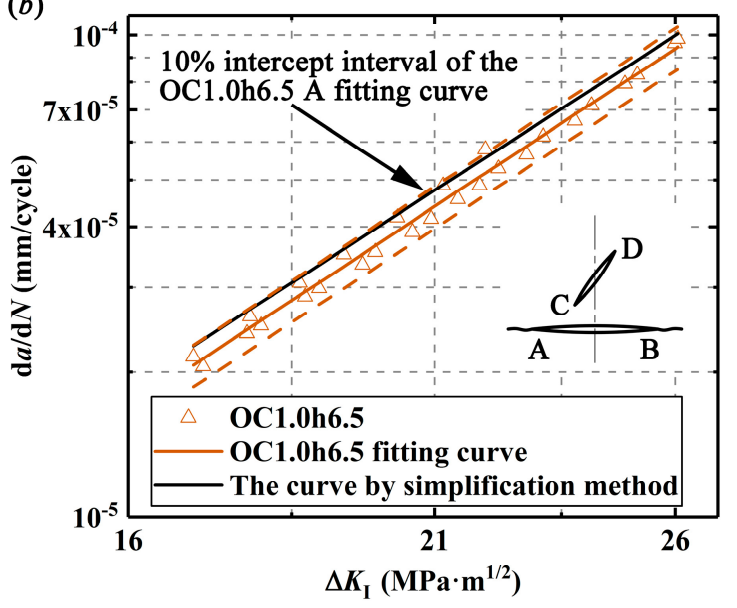

Figure 16. Simplification results for the double oblique cracks: (a) In OC0.9h6.1 specimens; (b) in OC1.0h6.5 specimens.

Both the AMSE method and the simplification method here simplify the double cracks into a single crack, and the length of the single crack for the double cracks studied here is equal to the projected length of the dominant crack. For comparison, Table 4 lists the results of the ASME method and the simplification method proposed here, where $N 1$ is the cycle numbers obtained from the experiments when the crack tip A propagates $10 \mathrm{~mm}, \mathrm{~N} 2$ and $\mathrm{N} 3$ are the cycles calculated by equivalent single cracks based on the ASME method and the simplification method here, respectively. Clearly, the simplification method proposed here is much more accurate than the ASME method.

Table 4. Comparison of the two methods.

\begin{tabular}{cccccc}
\hline \multirow{2}{*}{ Specimens } & Required Cycle & \multicolumn{2}{c}{ The ASME Method } & The Method Proposed In This Paper \\
\cline { 2 - 5 } & N1 & N2 & Error (\%) & N3 & Error (\%) \\
\hline PC0.5h5 & 166,144 & 145,581 & $12.38 \%$ & 159,223 & $4.17 \%$ \\
PC0.7h4 & 182,787 & 145,581 & $20.35 \%$ & 175,709 & $3.87 \%$ \\
PC0.9h2.5 & 194,984 & 145,581 & $25.34 \%$ & 209,973 & $7.69 \%$ \\
PC1.0h2.5 & 261,526 & 145,581 & $44.33 \%$ & 273,873 & $4.72 \%$ \\
OC0.9h6.1 A & 186,999 & 145,581 & $22.15 \%$ & 204,655 & $9.44 \%$ \\
OC1.0h6.5 A & 293,306 & 145,581 & $50.37 \%$ & 267,715 & $8.73 \%$ \\
\hline
\end{tabular}

In engineering structures, multi-cracks usually exist and how to simplify them makes a complicated problem. Although only two cracks are studied here, the new method here could be applied to multi-cracks. Specifically, the first step is to find a dominant crack in the multi-cracks, which should be 
longer in the projected length perpendicular to the main loading. Then other cracks are dealt one by one by considering effects on the dominant crack. In this way, all other cracks could be considered theoretically. In addition, with equations proposed in this paper to modify stress intensity factors and material parameters in Paris equation, the stress intensity factors and crack growth rates can be calculated without establishing numerical models any more. It is also noted that by finding the dominant crack and considering effects of other cracks in the multi-cracks, the computation results are more accurate than the other methods applied in engineering.

\section{Conclusions}

In this study, interactions between double cracks with co-bisector-line are investigated through experiments and numerical simulations. Conclusions are obtained as follows:

(1) For the considered double cracks, they present shielding interactions on the stress intensity factors at crack tips and crack growth rates, which can be explained from the mechanical point of view.

(2) The $\mathrm{d} a / \mathrm{d} N-\Delta K_{\mathrm{I}}$ curves of the dominant crack propagation in the double cracks studied here deviate from those of the single crack. The more the crack shielding effects, the less the crack growth rates of the dominant crack.

(3) As crack shielding interaction may also shield the damage of the material around the crack tips, the Paris equation for the single crack propagation is not quite suitable to describe multi-crack propagation.

(4) Reliable formulas are proposed to calculate the SIFs of the dominant crack with considering the shielding effects by the other crack, and a new method is proposed to simplify the double cracks into a single crack with the same crack growth rates.

(5) The simplification method proposed in this paper is much more accurate than the ASME method, and the error of the method is less than $10 \%$. Theoretically it can be applied to multi-crack configurations in engineering structures.

Author Contributions: Conceptualization: Z.H. and C.Q.; methodology: Z.H.; software: Z.H.; validation: Z.H., and H.L.; formal analysis: H.L.; investigation: Z.H.; resources: C.Q.; data curation: H.L.; writing-original draft preparation: Z.H.; writing-review and editing: C.Q.; visualization: C.Q.; supervision: Z.H.; project administration: Z.H.; funding acquisition: C.Q. All authors have read and agreed to the published version of the manuscript.

Funding: This research received no external funding.

Conflicts of Interest: The authors declare no conflict of interest.

\section{Appendix A}
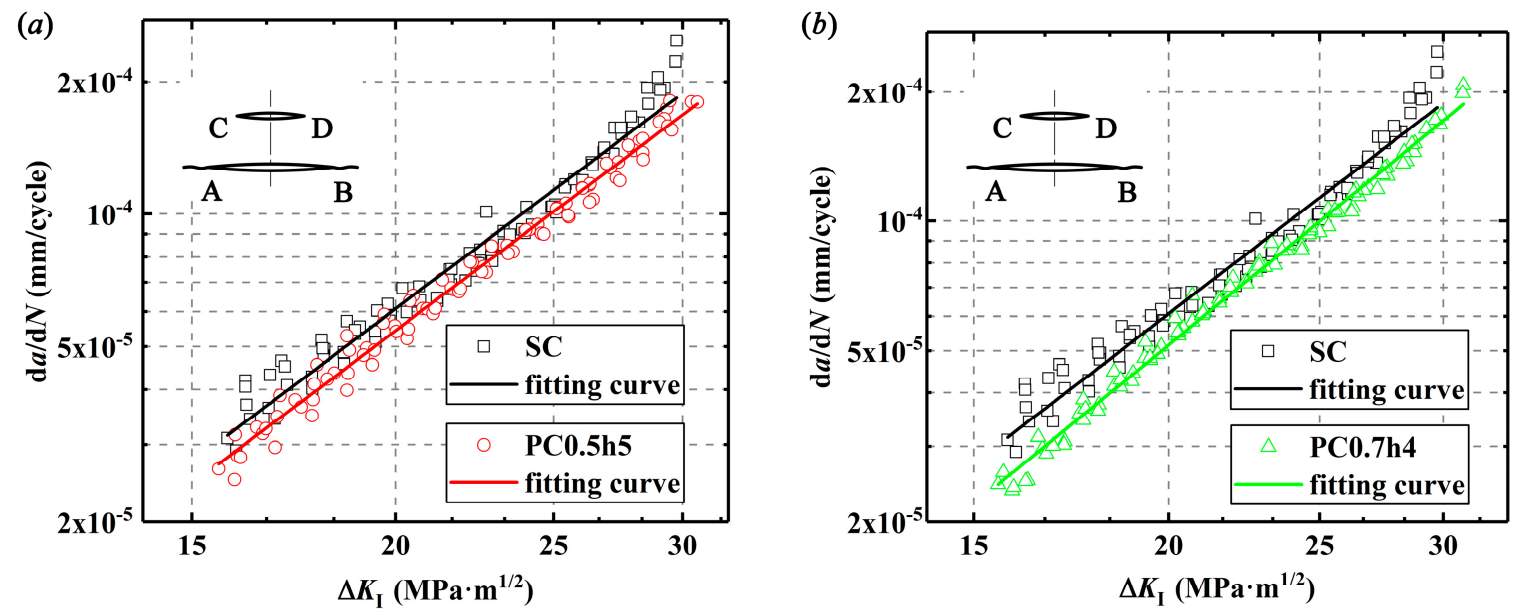

Figure A1. Cont. 
(c)

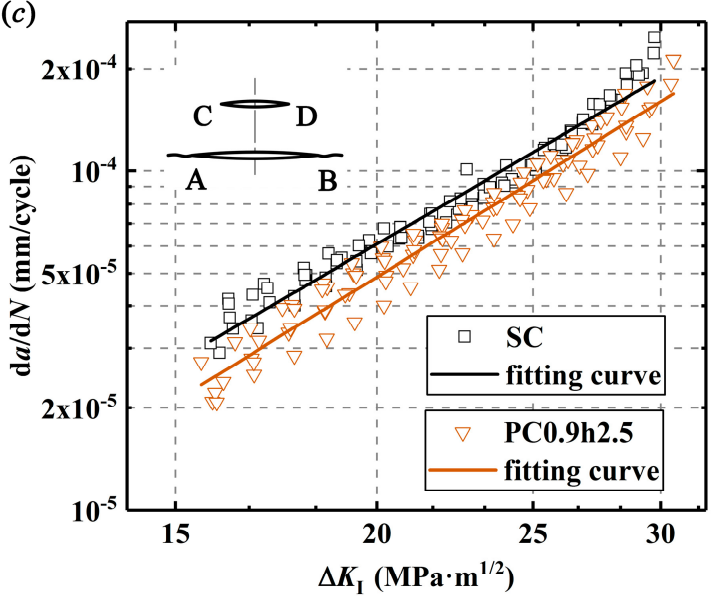

(d)

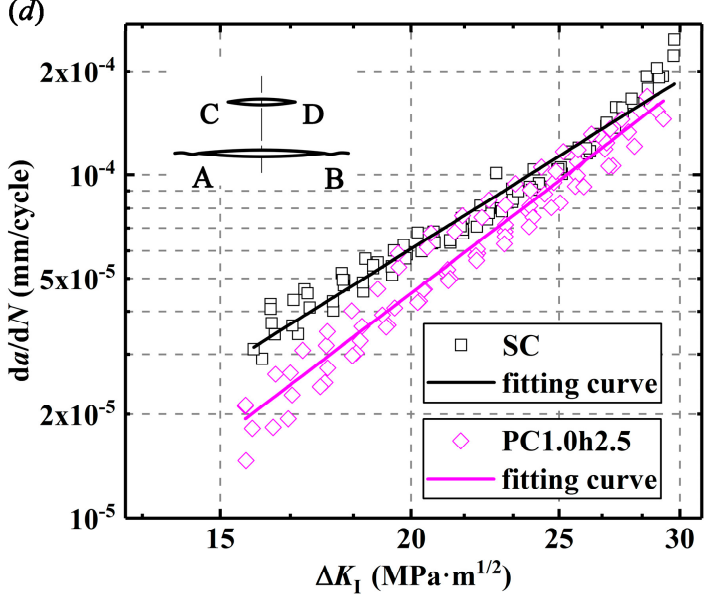

Figure A1. Fatigue crack growth rates versus $\Delta K_{\mathrm{I}}$ for different specimens: (a) SC and PC0.5h5; (b) SC and PC0.7h4; (c) SC and PC0.9h2.5; (d) SC and PC1.0h2.5.
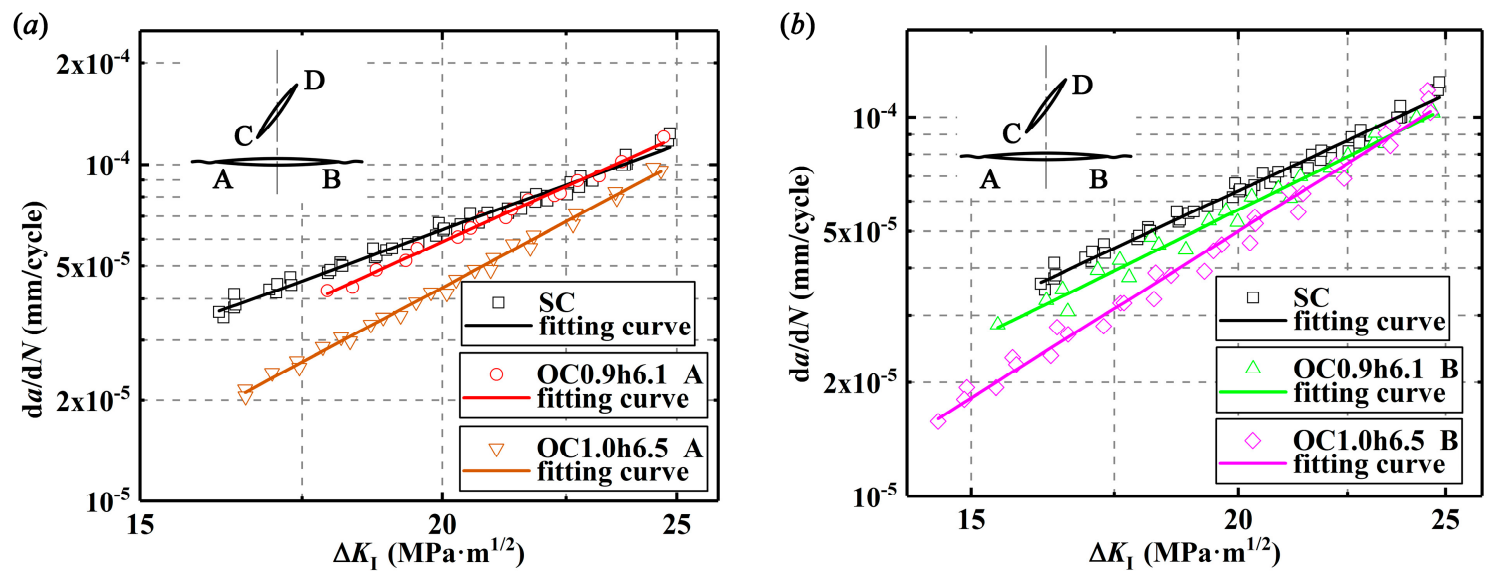

Figure A2. Fatigue crack growth rates versus $\Delta K_{\mathrm{I}}$ for different specimens: (a) SC and OC0.9h6.1; (b) SC and OC1.0h6.5.

\section{References}

1. Tang, L.; Qian, C.; Ince, A.; Li, H.; Zhang, X. The effect of strain strengthening on the mixed mode crack fatigue propagation in the HAZ of 06Cr19Ni10 stainless steel. Mater. Sci. Eng. A 2017, 698, 341-347. [CrossRef]

2. Srivastava, A.K.; Arora, P.K.; Kumar, H. Numerical and experiment fracture modeling for multiple cracks of a finite aluminum plate. Int. J. Mech. Sci. 2016, 110,1-13. [CrossRef]

3. Huang, W.; Garbatov, Y.; Soares, C.G. Fatigue reliability assessment of a complex welded structure subjected to multiple cracks. Eng. Struct. 2013, 56, 868-879. [CrossRef]

4. Chai, G.; Zhang, K. Stress intensity factors for interaction of surface crack and embedded crack in a cylindrical pressure vessel. Press. Vessel. Pip. 2000, 77, 539-548. [CrossRef]

5. Dündar, H.; Ayhan, A.O. Three-dimensional fracture and fatigue crack propagation analysis in structures with multiple cracks. Comput. Struct. 2015, 158, 259-273. [CrossRef]

6. Kamaya, M. A Crack Growth Evaluation Method for Interacting Multiple Cracks. JSME Int. J. Ser. A 2003, 46, 15-23. [CrossRef]

7. Kim, E.; Choi, H.; Park, K.; Kang, W. Deterministic and Probabilistic Investigation on Multiple Crack Interactions in a Semi-Infinite Domain. Math. Probl. Eng. 2015, 2015, 1-9. [CrossRef]

8. Mahadevan, S.; Shi, P. Corrosion fatigue reliability of aging aircraft structures. Prog. Struct. Eng. Mater. 2001, 3, 188-197. [CrossRef] 
9. Tan, J.T.; Chen, B.K. Prediction of fatigue life in aluminium alloy (AA7050-T7451) structures in the presence of multiple artificial short cracks. Theor. Appl. Fract. Mech. 2015, 78, 1-7. [CrossRef]

10. Shu, Y.; Li, Y.; Duan, M.; Yang, F. An X-FEM approach for simulation of 3-D multiple fatigue cracks and application to double surface crack problems. Int. J. Mech. Sci. 2017, 130, 331-349. [CrossRef]

11. Zerbst, U. Application of fracture mechanics to welds with crack origin at the weld toe-a review. Part 2: Welding residual stresses. Residual and total life assessment. Weld. World 2020, 64, 151-169. [CrossRef]

12. Bech, J.I.; Mikkelsen, L.P. Micromechanisms of leading edge erosion of wind turbine blades: X-ray tomography analysis and computational studies. Wind Energy 2019, 2019, 1-16.

13. Zhu, S.; Hao, Y.; Liao, D. Probabilistic modeling and simulation of multiple surface crack propagation and coalescence. Appl. Math. Model. 2020, 78, 383-398. [CrossRef]

14. Liao, X.; Wang, Y.; Wang, Z.; Feng, L.; Shi, Y. Effect of low temperatures on constant amplitude fatigue properties of Q345qD steel butt-welded joints. Eng. Fail. Anal. 2019, 105, 597-609. [CrossRef]

15. Wang, Y.; Zheng, Y. Research on Corrosion Fatigue Performance and Multiple Fatigue Sources Fracture Process of Corroded Steel Wires. Adv. Civ. Eng. 2019, 2019, 1-25. [CrossRef]

16. Yoshinaka, F.; Sawaguchi, T. Characterization of crystallographic fracture surfaces in Fe-33Mn-6Si alloy. Int. J. Fatigue 2020, 130, 105271. [CrossRef]

17. Zhang, B.; Du, L.X.; Dong, Y.; Han, D.X.; Wu, H.Y.; Lu, F.H.; Misra, R.D.K. Structure-property relationship in novel low carbon hot-rolled TRIP steels via thermo-mechanical controlled processing and coiling. Mater. Sci. Eng. A 2020, 771, 4-12. [CrossRef]

18. Li, P.; Sun, Q.; Xiao, L.; Sun, J. Tuning the morphology of Ti-5Al-5Mo-5V-3Cr-1Zr alloy: From brittle to ductile fracture. Mater. Sci. Eng. A 2020, 769, 138487. [CrossRef]

19. Gope, P.C.; Bisht, N.; Singh, V.K. Influence of crack offset distance on interaction of multiple collinear and offset edge cracks in a rectangular plate. Theor. Appl. Fract. Mech. 2014, 70, 19-29. [CrossRef]

20. Elfakhakhre, N.R.F.; Long, N.M.A.N.; Eshkuvatov, Z.K. Stress intensity factor for an elastic half plane weakened by multiple curved cracks. Appl. Math. Model. 2018, 60, 540-551. [CrossRef]

21. Moussa, W.A.; Bell, R.; Tan, C.L. The interaction of two parallel non-coplanar identical surface cracks under tension and bending. Int. J. Press. Vessel. Pip. 1999, 76, 135-145. [CrossRef]

22. Moussa, W.A.; Bell, R.; Tan, C.L. The Interaction of Two Parallel Semi-Elliptical Surface Cracks Under Tension and Bending. J. Press. Vessel. Technol. 2014, 121, 323-326. [CrossRef]

23. Moussa, W.A.; Bell, R. Investigating the Effect of Crack Shape on the Interaction Behavior of Noncoplanar Surface Cracks Using Finite Element Analysis. J. Press. Vessel. Technol. 2014, 124, 234-238. [CrossRef]

24. Isida, M.; Igawa, H. Some asymptotic behavior and formulae of stress intensity factors for collinear and parallel cracks under various loadings. Int. J. Fract. 1994, 65, 247-259.

25. Jiang, Z.D.; Zeghloul, A.; Bezine, G.; Petit, J. Stress intensity factors of parallel cracks in a finite width sheet. Eng. Fract. Mech. 1990, 35, 1073-1079. [CrossRef]

26. Jiang, Z.D.; Petit, J.; Bezine, G. An investigation of stress intensity factors for two unequal parallel cracks in a finite width plate. Eng. Fract. Mech. 1992, 42, 129-138. [CrossRef]

27. Kishida, M.; Asano, M. A study of interference of three parallel cracks. Eng. Fract. Mech. 1984, 19, 531-538. [CrossRef]

28. Sun, W.; Zhu, Y.; Huo, J.; Chen, X. Multiple cracks failure rule for TBM cutterhead based on three-dimensional crack propagation calculation. Eng. Fail. Anal. 2018, 93, 224-240. [CrossRef]

29. Jin, H.J.; Wu, S.J. A new driving force parameter for fatigue growth of multiple cracks. Int. J. Fatigue 2017, 96, 10-16. [CrossRef]

30. Kamaya, M. Growth evaluation of multiple interacting surface cracks. Part I: Experiments and simulation of coalesced crack. Eng. Fract. Mech. 2008, 75, 1336-1349. [CrossRef]

31. Han, Z.C.; Qian, C.F.; Tang, L.Q.; Li, H.F. Determination of the enhancement or shielding interaction between two parallel cracks under fatigue loading. Materials 2019, 12, 1331. [CrossRef]

32. Sabbagh-Yazdi, S.R.; Farhoud, A.; Asil, G.S. Simulation of 2D linear crack growth under constant load using GFVM and two-point displacement extrapolation method. Appl. Math. Model. 2018, 61, 650-667. [CrossRef] 
33. Kuang, J.H.; Chen, C.K. Equivalence for two interacting parallel cracks. J. Press. Vessel. Technol. 1998, 120, 424-430. [CrossRef]

34. ASME. Rules for In-Service Inspection of Nuclear Power Plant Components. In ASME Boiler and Pressure Vessel Code; Section XI; American Society of Mechanical Engineers: New York, NY, USA, 2017.

(C) 2020 by the authors. Licensee MDPI, Basel, Switzerland. This article is an open access article distributed under the terms and conditions of the Creative Commons Attribution (CC BY) license (http://creativecommons.org/licenses/by/4.0/). 